\title{
Poéticas y cánones literarios bajo el franquismo
}

Fernando Larraz y Diego Santos Sánchez (Eds.)

Madrid/Frankfurt am Main, Iberoamericana/Vervuert, 2021, 326 pp.

Esta miscelánea, publicada en la editorial Iberoamericana/Vervuert, agrega una pieza notable a la ambiciosa serie "La Casa de la Riqueza. Estudios de la Cultura de España". La colección surgió con una finalidad bien definida: extender el debate sobre la memoria histórica y, a la vez, investigar las consecuencias en la Espańa contemporánea del reciente pasado. Como se lee en la declaración de intenciones que abre el libro, la Casa de la Riqueza apunta a "[...] contribuir a la apertura de nuevos espacios críticos en España a través de la publicación de trabajos que den cuenta de los diversos lugares teóricos y geopolíticos desde los cuales se piensa el pasado y el presente español". El volumen editado por Fernando Larraz (Universidad de Alcalá) y Diego Santos Sánchez (Universidad Complutense de Madrid) sigue a la letra esta línea programática: por un lado, por su enfoque innovador y multidisciplinar $y$, por otro, por el constante diálogo que se instaura entre los fenómenos históri- cos y sus reflejos en la actualidad.

Así pues, todos los ensayos recogidos en el volumen aspiran a desmontar los tópicos que se difundieron durante el franquismo, y que todavía - a cuarenta y seis años de la muerte del dictadorimpiden una correcta interpretación de las letras que se fraguaron a la sombra del "Nuevo Estado". Este libro colectivo nace pues de la necesidad —diríamos casi de la urgencia- de presentar una nueva interpretación crítica de los hechos literarios, superando los legados de un sistema que consiguió manipular también la historiografía $y$, por consiguiente, la percepción de las generaciones sucesivas. Se ambiciona superar, en definitiva, estas alteraciones, emprendiendo una reflexión que aporte nuevas perspectivas a la memoria histórica. Por ello, se dirige la atención a ámbitos poco explorados desde la academia y, a la vez, se revisan los cánones literarios que hasta la crítica actual ha leído a menudo a 
través de los filtros que engendró el franquismo.

El primer paso en este sentido es la rigurosa documentación histórica de los once capítulos aquí presentados. Los firman, además, especialistas de sectores distintos, cuyo perfil internacional y variedad de intereses contribuye a un enfoque aún más polifacético y heterogéneo. De este modo, se estudian distintas facetas de la producción que se desarrolló "bajo el franquismo": la historiografía, la crítica, la narrativa, el teatro, la poesía y los relatos de viajes. Los documentos examinados, además, pertenecen a tipologías variadas, e incluyen, junto a las obras literarias, expedientes de censura, ensayos, entrevistas, folletos y programas de mano de pièces, epistolarios, periódicos y revistas de la época. A pesar de la vastedad de los asuntos y de la abundancia de las herramientas, el lector se encuentra, no obstante, con una obra cohesionada, que hace de un conjunto de ensayos una relectura tout court de las poéticas de la posguerra. Por esta razón, podemos considerarlos como capítulos de un único recorrido. Son dos los objetivos que los unen. En primer lugar, el afán de infringir categorías historicistas, etiquetas poéticas y someros jui- cios que han ido sedimentándose en la crítica y que han terminado configurando una memoria hecha por y para el régimen; se pretende investigar dentro de los entresijos de una fase histórica erróneamente considerada monolítica y regida por paradigmas inalterables. $\mathrm{Y}$, en segundo lugar, los ensayos se proponen rescatar de los resquicios de la historia esos fermentos culturales que, precisamente fuera de los cánones consagrados, han permanecido en los márgenes de la historia oficial.

En definitiva, desde una perspectiva más general, podemos afirmar que el libro, en su conjunto, abarca una cuestión de gran envergadura: pretende arrojar luz sobre la conflictiva y ambivalente relación entre la literatura y el contexto histórico que la produjo, indagando en las interconexiones entre el campo cultural y el Estado. En un régimen represivo y omnipresente en todas las facetas de la sociedad como el franquista, los vínculos de orden político, ideológico o estratégico a menudo primaron sobre los criterios estéticos y dirigieron o influenciaron tanto los cánones, como el gusto literario.

El concepto que mejor sintetiza esta inextricable trabazón aparece ya en el título de la introducción: 
"La literatura bajo el franquismo: anomalías de un sistema" (pp. 9-26). Con "anomalías" - necesariamente en plural- los editores hacen referencia a los condicionamientos que tuvieron que sufrir escritores, traductores, editores, libreros, empresarios y todos los agentes, en general, involucrados en la industria cultural. De una manera muy clara, Larraz y Santos Sánchez afirman que no se puede leer la literatura de posguerra prescindiendo de la asfixiante presencia de la dictadura, como si la creación intelectual y artística fuera neutra o abstracta $y$, por ende, ajena a las contingencias. Contingencias tan trágicas, en este caso, como la Guerra Civil y el nacimiento de un estado totalitario que, en su sed de control, extendió sus tentáculos a cada aspecto de la cultura: prohibió libros o impidió sus importaciones, fichó y vigiló a escritores y editores, vedó espectáculos teatrales y películas, influyó en premios literarios y, no menos importante, favoreció o dificultó a determinados autores y géneros. Una dictadura que, además, fue responsable de la mayor y más dramática anomalía de la historia contemporánea española: la diáspora de los exiliados y la consiguiente escisión del mundo intelectual.
Los editores enumeran las otras anomalías que hicieron de España un caso único en el mapa europeo: la imposición del castellano en detrimento de las otras lenguas peninsulares; la cerrazón cultural hacia todo lo que venía de más allá de los Pirineos; y la dispersión del gran fervor creativo de la época republicana. Finalmente, fue vistosamente "anómala" la instauración de un órgano ministerial encargado de controlar y juzgar con criterios de ortodoxia moral, política y religiosa cada página que se imprimía en el Estado. Pero a la manifiesta censura de los bolígrafos rojos de los funcionarios que rastreaban los manuscritos antes de su publicación, se añadía otra, menos tangible pero igualmente culpable de la forzada alteración de los cánones: la autocensura. Los escritores, pues, se vieron forzados a elaborar diferentes estrategias para sortear prohibiciones y mutilaciones. La existencia de la censura institucionalizada tuvo como primera consecuencia la desaparición de determinados temas y lenguajes prohibidos, incluso antes de que los mecanografiados entraran en las oficinas ministeriales. Y, además, los escritores que querían ver sus obras publicadas fueron obligados a dirigirse hacia creaciones 
inocuas o a servirse de simbologías ocultas para denunciar de manera más o menos directa el sistema. Todo esto contribuyó a la creación de poéticas que, en un contexto de libertad de expresión, probablemente no hubieran ensayado.

Sin embargo, todas estas anomalías se convirtieron en normas en el sofocante ambiente cultural del régimen, y se propagaron en una sociedad que, con el tiempo, dejó de percibirlas como medidas extraordinarias de un estado de excepción. En este contexto la crítica creó "cánones" que los mismos lectores aceptaron e interiorizaron. Podemos afirmar que el sistema había conseguido su propósito, siendo asimilado por todos, incluso por sus enemigos internos. Como se subraya en distintas ocasiones en el volumen, la misma obra de los opositores culturales (Carlos Barral y Josep Castellet in primis) nacía en el seno del régimen, y no consiguió apartarse del todo de su dominio. En efecto, el grupo fomentó una tendencia estética —el realismo comprometido - que aspiraba a ser innovadora y "de signo opuesto" con respecto a las poéticas oficiales, pero que constituyó un canon rígido y excluyente, que se sustentaba en parecidos prejuicios y simplificaciones teóricas. Este contra-canon, en definitiva, fue condicionado por la misma cultura hegemónica que quería contrastar, como un espejo que reflejaba —aunque al revés- sus metodologías.

Veamos pormenorizadamente, aunque de forma sucinta, las "anomalías" señaladas en el volumen. Valeria De Marco de la Universidad de São Paulo firma el primer capítulo: "Ceguera estética e historiografía literaria en la era de Franco" (pp. 27-53). La estudiosa extiende su análisis a todo el siglo $\mathrm{xx}$ para demonstrar que el retraso espańol se remonta a los decenios anteriores a la contienda civil. El franquismo hizo suyo el método anticientífico de Menéndez Pelayo que se fundamentaba en una estrecha conexión entre lengua, nación y tradición literaria como parámetro de valoración. En la posguerra esta deformación crítica se institucionalizó, enalteciendo una historiografía antihistórica de claro signo católico. El capítulo siguiente, de Max Hidalgo Nácher (Universitat de Barcelona), titulado "Genealogía de la teoría literaria y herencias teóricas del franquismo: la estilística y la renovación crítica de los ańos sesenta” (pp. 55-80), aborda el discurso teórico e historiográfico del segundo franquismo, 
especialmente a través de la trayectoria de Dámaso Alonso. En los años cuarenta el crítico madrileño apostó por una visión espiritualista de la literatura que se conciliaba a la perfección con la ideología nacional-católica propugnada por el régimen. Este connubio condujo a otra especificidad: el nacimiento de una estilística "a lo divino" y el consiguiente retraso en la penetración del estructuralismo, de los estudios comparatistas y de la obra de Barthes, Foucault o Lévi-Strauss en España.

Con el capítulo de Rocío Ortuño Casanova ("Nostalgia del imperio: literatura filipina y franquismo", pp. 81-108) se empiezan a abordar casos particulares en cuanto a la alteración de cánones. La especialista de la Universidad de Antwerpen documenta, aportando distintos ejemplos, cómo la intelectualidad del régimen enalteció la historia de Filipinas y, en especial, la anacrónica poesía en español de la colonia de principios de siglo. Esta lectura nostálgica y épica nacía de ese ideal de panhispanismo que todavía animaba los sectores más ideologizados del Movimiento.

En "Teatro y censura desde la dictadura franquista: de la prohibición a la formación del canon" (pp. 109-134), Berta Muñoz Cáliz, del Instituto del Teatro de Madrid, estudia la política intervencionista del régimen con respecto a las obras dramáticas, un campo considerado especialmente "peligroso" por su amplio alcance social. La estudiosa complementa las informaciones sobre los avatares censorios de los textos teatrales con los obstáculos en la puesta en escena. De esta manera, proporciona un cuadro global (a menudo ausente en las disertaciones sobre el tema) de las dificultades sufridas por los autores dramáticos $\mathrm{y}$, a su vez, muestra los intentos — no siempre logradosde dirigir desde arriba sus poéticas.

Los capítulos siguientes nos ofrecen una reflexión crítica de la obra y los axiomas de los ya citados jóvenes "realistas" liderados por Barral y Castellet. En el tratamiento del grupo se matiza la usual contraposición de esta "escuela" con la cultura dominante para mostrar el autoritarismo de sus postulados.

Geneviève Champeau, de la Université Bordeaux Montaigne, analiza en "Ideologías, poéticas y canon: el relato de viaje bajo el franquismo" (pp. 135-158), el avance de la poética del compromiso social a través de un género fronterizo como el relato de viaje. Explica que las crónicas realistas tenían explícitos objetivos políticos que guiaban 
también sus posturas estéticas. En sus crónicas, pues, quisieron subvertir las narraciones míticas, épicas y grandilocuentes de la propaganda, y para lograrlo invirtieron su imaginario y sus símbolos. De esta manera fraguaron un canon que no conseguía apartarse de una lectura ideologizada del viaje y reproducía, aunque al revés, la retórica oficial.

Juan José Lanz, profesor en la Universidad del País Vasco, en "Canon y campo literario en la poesía española bajo el franquismo (1939-1955)" (pp. 159-188), en cambio, dirige su mirada a la poesía. Su capítulo comienza con un excursus sobre el cambiante concepto de canon, o, mejor dicho, de cánones. El autor advierte, además, que la historiografía española ya desde el principio del siglo $\mathrm{xx}$ se ha esforzado por enmarcar los poetas dentro de precisas coordenadas temático-estilísticas o generacionales. Durante el franquismo tales ambiguos marcos (fueran los del neoclasicismo formalista los del realismo social) llevaron a la marginación de los autores que no se homologaron y que abrazaron poéticas "heterodoxas" como las del simbolismo, de la neo-vanguardia o del hedonismo vitalista.

María Teresa Navarrete Navarrete (Uppsala Universitet) continúa abordando el estudio de la trayectoria poética en la España franquista en su capítulo "1959: triunfos, discordias y paradojas en el canon de la poesía del medio siglo" (pp. 189-210). Como se ve, su punto de partida es la célebre conmemoración machadiana de Coillure. A partir de ese año simbólico, el grupo liderado por Barral y Castellet emprendió una verdadera campaña de auto promoción, respaldando "agresivamente" (p. 201) los autores que adhirieron al nuevo diktat con una colección que tomó su nombre de la aldea donde falleció el poeta andaluz. Para ofrecer a los adeptos del realismo comprometido una rigurosa colocación, la escuela utilizó, de nuevo, los mismos métodos y categorías del régimen impulsando la imagen de una escuela cohesionada y unida por fuertes afinidades estéticas, políticas y cronológicas. Esta artificiosa proyección —creada para el uso y consumo de editores, crítica y lectores - escondía en realidad numerosas contradicciones y un mosaico de posiciones distintas. La rigidez del canon llevó también a la dispersión de otros núcleos poéticos (como el de Madrid o el andaluz) que no se adecuaron a la "operación realismo" que los jóvenes antifranquistas consideraban la única vía hacia la modernidad. 
A continuación encontramos dos capítulos que documentan cómo esta visión incuestionable y unilateral del grupo catalán condicionó también sus reflexiones teóricas, su producción narrativa y su relación con los exiliados. Bénédicte Vauthier, de la Universität de Bern, se ocupa en "A deshora, 1956-1963, "literatura responsable" y engagement" (pp. 211-250) del teórico del grupo, Castellet, como caso paradigmático de los exiguos contactos que mantuvo su generación con los intelectuales desterrados en 1939. Fueron precisamente los llamados "niños de la guerra" los que se alejaron de un pasado que había llegado a ser incómodo. Así llegó demasiado tarde (“A deshora” del título) también el importante volumen Problemática de la literatura (Buenos Aires, Losada, 1951) de Guillermo de Torre, exiliado en la capital argentina. Según Bénédicte Vauthier, la idea de "literatura responsable" que promovía el ensayo habría podido matizar la rigurosa teoría de creación engagée de derivación sartriana que se difundió en la Península. Al final del capítulo se transcribe una parte del epistolario entre Castellet y Guillermo de Torre formado por ocho cartas inéditas (del fondo de la Biblioteca Nacional de España) que los dos intelectuales se cruzaron entre 1957 y 1963. Las cartas son importantes no solo para reconstruir la génesis de sus obras, sino también porque proporcionan una ulterior señal de la fragilidad del puente entre dos generaciones, tan solo aparentemente unidas bajo la bandera del antifranquismo.

Un puente que, como observa Fernando Larraz en "Una lectura imposible: el unilateralismo realista peninsular ante la recepción de la narrativa del exilio (1958-1963" (pp. 251-276), se hizo aún más asimétrico en los años cincuenta. Los críticos y autores de la Generación del Medio Siglo utilizaron la misma vulgata que el franquismo para recalcar su distancia - poética y anagráfica antes que física- con los exiliados. De una forma análoga a los intelectuales falangistas sacralizaron conceptos como "lo nuevo" y "la juventud" para celebrar su ruptura con la etapa republicana. Teorizaron, entonces, un artificioso enfrentamiento que se basaba en la contraposición entre el moderno realismo (que le contaba al lector español su vivo presente) y la arcaica literatura de los exiliados, obsesionados por el recuerdo de la Guerra y todavía aferrados al idealismo orteguiano. Como concluye Larraz, esta lectura simplificada del 
realismo comprometido "supuso una losa para las posibilidades de que la narrativa exiliada llegara a inspirar los aires renovadores de la novela peninsular que comenzaban a soplar" (p. 274).

Domingo Ródenas de Moya (Universitat Pompeu Fabra), en su "Questo libro non è per te: la neovanguardia narrativa al filo de 1970” (pp. 277-295), continúa el itinerario de la narrativa posbélica. Así llega hasta los últimos años de la dictadura, cuando vieron la luz otras obras que se alejaron de las convenciones y, por eso, han caído en el olvido. Las experimentaciones que siguieron la temporada del compromiso civil fueron, en efecto, tan poco convencionales que no consiguieron - y a menudo no quisieron - imponerse a la atención de la crítica y del lector. Sin embargo, son testimonios de un momento de apertura y de la existencia de voces periféricas. $\mathrm{Su}$ importancia radica en su búsqueda de fuentes hasta entonces inexploradas en España, como la obra del vanguardista italiano Edoardo Sanguineti o de la controcultura beat.

El capítulo final de Cristina Suárez Toledano de la Universidad de Alcalá ("Autores y obras llegadas desde el otro lado del Atlántico: la recepción de la literatura hispano- americana en España durante el franquismo", pp. 297-318), por último, dirige la atención a las causas del llamado boom hispanoamericano. La estudiosa demuestra que en su penetración fueron decisivos factores extraliterarios, en los que confluyeron intereses del régimen y de sus opositores. Por un lado, acoger la nueva ola narrativa le brindaba a la propaganda de la dictadura la oportunidad de fingir una nueva apertura al exterior y divulgar la idea de que todas las "anomalías" se habían superado. Por otro, los editores antifranquistas jugaron un papel activo en su afán de hacerse portavoces de un canon innovador que desplazara el desgastado realismo social. Por ello, asignaron a los novelistas hispanoamericanos otra etiqueta general, empleando los parámetros tantas veces ensayados por la historiografía oficial (generación, amistad y poética común). De esta manera permitían su inmediata identificación como grupo, aunque al precio de trivializar su obra y ocultar sus especificidades individuales.

Con este capítulo llegamos al final del franquismo. Como se decía, tampoco la disgregación de la dictadura significó la caída de todas las “anomalías" surgidas en esos largos decenios; anomalías que esta misce- 
lánea contribuye a reconstruir y, sobre todo, a superar. Su gran mérito, como dijimos, es el de mellar la narración que el franquismo hizo de sí mismo, contrastándola con una lectura más profunda y exenta de condicionamientos. Podemos decir que los propósitos del volumen son aún más ambiciosos. Los capítulos recogidos ilustran un paradigma metodológico que puede ser precursor para estudios que vayan en la misma dirección, y que igualmente aporten nuevas perspectivas de la memoria histórica. Como indicaban los editores, esperamos que Poéticas y cánones literarios bajo el franquismo se convierta en "un punto de partida para nuevas interpretaciones, más cabales, complejas y problematizadas, de un periodo excepcional de la historia literaria española” (p. 26).

Cierra el libro (pp. 319-326) un resumen de los currículos y de las principales publicaciones de cada estudioso. Señalamos, por último, que no hay una única lista de las obras citadas, sino que cada capítulo va acompañado de su propia bibliografía completa y actualizada.

\section{Andrea Bresadola} Università di Macerata 